\title{
Gradient of Residual Stress and Lattice Parameter in Mechanically Polished Tungsten Measured Using Classical X-rays and Synchrotron Radiation
}

\author{
ADRIAN OPONOWICZ, MARIANNA MARCISZKO-WIACCKOWSKA, ANDRZEJ \\ BACZMAŃSKI, MANUELA KLAUS, CHRISTOPH GENZEL, SEBASTIAN WROŃSKI, \\ KAMILA KOLLBEK, and MIROSŁAW WRÓBEL
}

\begin{abstract}
In this work, the stress gradient in mechanically polished tungsten sample was studied using $\mathrm{X}$-ray diffraction methods. To determine in-depth stress evolution in the very shallow subsurface region (up to $10 \mu \mathrm{m}$ ), special methods based on reflection geometry were applied. The subsurface stresses (depth up to $1 \mu \mathrm{m}$ ) were measured using the multiple-reflection grazing incidence X-ray diffraction method with classical characteristic X-rays, while the deeper volumes (depth up to $10 \mu \mathrm{m}$ ) were investigated using energy-dispersive diffraction with white high energy synchrotron beam. Both complementary methods allowed for determining in-depth stress profile and the evolution of stress-free lattice parameter. It was confirmed that the crystals of tungsten are elastically isotropic, which simplifies the stress analysis and makes tungsten a suitable material for testing stress measurement methods. Furthermore, it was found that an important compressive stress of about - $1000 \mathrm{MPa}$ was generated on the surface of the mechanically polished sample, and this stress decreases to zero value at the depth of about $9 \mu \mathrm{m}$. On the other hand, the strain-free lattice parameter does not change significantly in the examined subsurface region.
\end{abstract}

https://doi.org/10.1007/s11661-020-05967-y

(C) The Author(s) 2020

\section{INTRODUCTION}

TUnGSTEN (W) is an elastically isotropic metal with a body-centered cubic (bcc) structure, having the highest melting temperature $\left(3422{ }^{\circ} \mathrm{C}\right)$ and the lowest thermal expansion coefficient $\left(4.5 \times 10^{-6} \mathrm{~m} / \mathrm{mK}^{[1]}\right)$ of any pure metal. Its density, equal to $19.3 \mathrm{~g} / \mathrm{cm}^{3}$, is the same as that of gold and higher than that of uranium. Only a few currently known stable pure metals have a higher density (i.e., Os, $\mathrm{Ir}, \mathrm{Pt}, \mathrm{Rh}, \mathrm{Np}$, and $\mathrm{Pu}){ }^{[2]}$ Tungsten thermal conductivity is equal to 174,159 and $146 \mathrm{~W} / \mathrm{mK}$ for temperatures of 300,400 and $500 \mathrm{~K}$, respectively. ${ }^{[3]}$ Relatively high strength and stiffness at high temperatures, together with an excellent corrosion resistance as well as a relatively low price,

ADRIAN OPONOWICZ, ANDRZEJ BACZMAŃSKI, and SEBASTIAN WROŃSKI are with the AGH-University of Science and Technology, WFiIS, al. Mickiewicza 30, 30-059 Kraków, Poland. MARIANNA MARCISZKO-WIĄCKOWSKA and KAMILA KOLLBEK are with the AGH-University of Science and Technology, ACMIN, al. Mickiewicza 30, 30-059 Kraków, Poland. Contact e-mail: marciszk@agh. edu.pl MANUELA KLAUS and CHRISTOPH GENZEL are with the Abteilung für Mikrostruktur- und Eigenspannungsanalyse, HelmholtzZentrum Berlin für Materialien und Energie, Albert-Einstein-Str. 15, Berlin 12489, Germany. MIROSŁAW WRÓBEL is with the AGH-University of Science and Technology, WIMiIP, al. Mickiewicza 30, 30-059 Kraków, Poland.

Manuscript submitted March 12, 2020.

Article published online September 4, 2020 makes tungsten one of the most commonly utilized hard metals, for example in the military, aerospace, nuclear, electronic and chemical industries. ${ }^{[4]}$ Tungsten can be used to produce structures working at a high temperature, radiation shields, and parts of a nuclear fusion reactor, ${ }^{[5-10]}$ multipinhole collimators for magnetic resonance devices, ${ }^{[1]}$ electrical switching contacts, magnetrons for microwave ovens, laser printers, air cleaners, and chemical reactors, etc. ${ }^{[12]}$

Surface finishing, such as polishing, is required for many engineering applications. Polishing not only increases the surface smoothness and thereby reduces the stress concentrators, but also changes the stress state in the subsurface layers. In addition, the reduction of surface roughness and the generation of compressive residual surface stresses have a positive effect on fatigue life, which is important in many industrial applications.

Polished tungsten products are widely available on the market (e.g., References 13 through 16) and several studies have been devoted to the effects of mechanical polishing on the performance and durability of parts made from this material. Like many body-centered cubic metals, tungsten exhibits a sudden ductile to brittle transition, which occurs at relatively high temperature (i.e., it is ductile above and brittle below ca. $130{ }^{\circ} \mathrm{C}$ ). Therefore, the reduction of cracking tendency is particularly important in the case of tungsten surface. ${ }^{[13-16]}$ It 
was found by Yuan et al. ${ }^{[17]}$ that surface residual stresses induced by mechanical polishing can strongly influence the surface cracking behavior occurring due to thermal cycling shocks during the electron beam irradiation.

Furthermore, attempts are being made to improve tungsten polishing techniques (e.g., References 18 through 20). They are mainly oriented to reducing the surface roughness, while the effect of polishing induced stresses is only marginally reported in the literature. ${ }^{[17]}$ The standard techniques for residual stress analysis allow scanning of lattice strains through the sample with a gauge volume of a few $\mathrm{mm}^{3}$ (neutron diffraction) or tens / hundreds of micrometers (synchrotron radiation) or provides an average value of biaxial stresses for a shallow depth under sample surface (of a few micrometers for common laboratory X-rays sources). In the case of polished samples, more precise methodologies for the measurements of residual stress gradient below the sample surface are demanded. Therefore, characterization of the residual stresses generated in subsurface layers of a commercial bulk polycrystalline tungsten due to mechanical polishing is the aim of the present work. For this study, nondestructive diffraction methods of the residual stress measurements using classical characteristic X-rays or synchrotron radiation are the most preferred. Hence, two methods, i.e., the multiple-reflection grazing incidence X-ray diffraction (MGIXD) ${ }^{[21-23]}$ based on angular diffraction (AD) and multiple-wavelength X-ray diffraction (MMXD) ${ }^{[24]}$ based on energy diffraction (ED), were applied in the present study. Such experimental techniques offer several benefits, among them the possibility to measure the depth profile of the residual stress being one of the most important ones.

\section{EXPERIMENTAL METHODS}

In this work, the so-called Laplace space methodology based on $\mathrm{AD}$ (with $\mathrm{Cu} \mathrm{K} \alpha$ radiation) and $\mathrm{ED}$ (with synchrotron radiation) techniques ${ }^{[22-27]}$ was applied to measure stresses $\sigma_{i j}$ and stress-free lattice parameter $a_{0}$ in the near surface layer of the mechanically polished tungsten. In this methodology, during the experiment, the information gauge is determined by exponential attenuation of the beam intensity, which can be characterized by penetration depth $\tau$, defined in Figure 1. The size of incident beam is formed by a set of slits in both techniques. In the case of $\mathrm{AD}$ technique and parallel beam configuration, the size of the diffracted beam is not limited, and its intensity is scanned versus $2 \theta$ angle with a parallel plate collimator placed in front of the point detector. Conversely, in the ED technique with white synchrotron radiation, narrow slits are applied to reduce divergence of the diffracted beam before energysensitive detector (Figure 1). The beam optics used in this work are described in References 22, 23, 28, and 29.

The first part of experiment was performed using XPert PANalytical X-ray diffractometer $(\mathrm{Cu} \mathrm{K \alpha}$ radiation) equipped with a Göbel mirror in the incidence beam optics. The MGIXD method, based on the AD technique, was applied to measure lattice strains at different depths close to the surface. Then, the ED technique with high energy synchrotron radiation at EDDI@BESSYII beamline (BESSY, HZG, Berlin $)^{[30]}$ to verify the results obtained by the MGIXD method and determine the variation of stresses for a much greater depth was compared to MGIXD. It should be stated that the classical ED- $\psi$ method $^{[27,31]}$ provides information from relatively greater depths when high energy synchrotron radiation is used instead of characteristic X-ray spectra, but the spatial resolution of this analysis is relatively low. Therefore, in this work, the MMXD method was applied, ${ }^{[24]}$ and in the analysis, the volume of the investigated sample was divided into separate thin layers. As the result, the stresses were determined layer by layer with better spatial resolution compared to the classical ED- $\psi$ method.

It should be emphasized that the presented methods of residual stress determination provides exponentially weighted ('Laplace space') depth profiles ( $v s$. penetration depth $\tau, c f$., Figure 1) and actual 'real space' residual stress profiles ( $v s$. depth $z$ under the surface of the sample, $c f$., Figure 1(a)) can be determined using inverse Laplace transform. ${ }^{[32]}$

\section{A. AD-MGIXD Method}

In the MGIXD method ${ }^{[21-23,26]}$ (based on AD technique), the beam of X-rays falls on the sample surface at very low incident angle $(\alpha)$, which is held fixed during the measurement (Figure 2(a)). Consequently, X-ray beam penetrates only a shallow and constant information depth in the studied material, which can be calculated from the formula:

$$
\tau=\left(\frac{\mu}{\sin \alpha}+\frac{\mu}{\sin \left(2 \theta_{h k l}-\alpha\right)}\right)^{-1}
$$

where $\mu$ is the linear absorption coefficient of X-rays and $2 \theta_{h k l}$ is the scattering angle, and the penetration depth $\tau$ is defined as the distance from the surface of bulk material for which $(1-1 / \mathrm{e})=0.63$ part of total intensity of the incident beam is absorbed.

In order to obtain the information from different penetration depths, it is necessary to set different angles of incidence $\alpha$. Using this method, not only the residual stress $\left(\sigma_{i j}\right)$ gradient can be determined non-destructively but also the depth-dependent profile of strain-free lattice parameter $\left(a_{0}\right)$ can be found.

Stresses can be determined using fundamental equations of X-ray stress analysis ${ }^{[33]}$ from the interplanar spacings $\langle d(\phi, \psi)\rangle_{h k l}$ measured at various directions of the scattering vector, i.e., for different angles between scattering vector and surface normal: $\psi_{h k l}=\theta_{h k l}-\alpha$. Consequently, the diffraction peaks must be determined for different $h k l$ reflections corresponding to appropriate $2 \theta_{h k l}$ angles and constant $\alpha$ angle (cf., Figure 2 (a)). ${ }^{[21,26,34,35]}$ In the case of multireflection methods, instead of $\langle d(\phi, \psi)\rangle_{h k l}$, the so-called equivalent lattice parameters $\langle a(\phi, \psi)\rangle_{h k l}=\langle d(\phi, \psi)\rangle_{h k l} \sqrt{h^{2}+k^{2}+l^{2}}$ (for cubic crystals) are used in the analysis. The values of measured $\langle a(\phi, \psi)\rangle_{h k l}$ depend on the values of macrostresses $\sigma_{i j}$ and strain-free lattice parameter $a_{0}$, i.e.: References 21: 


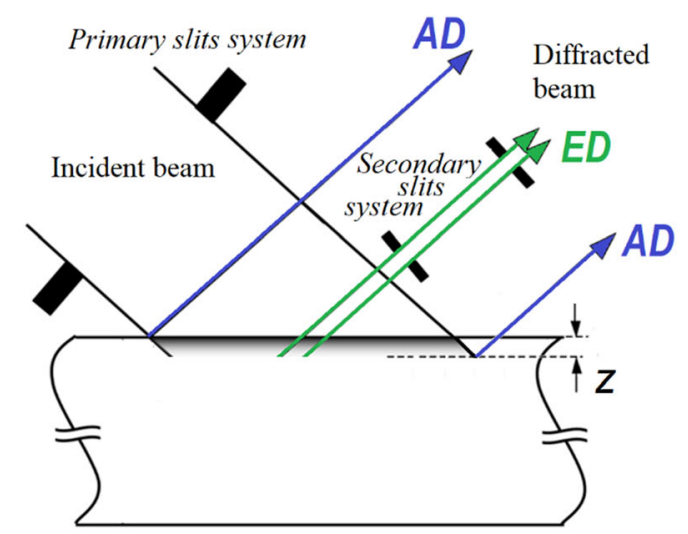

(a)

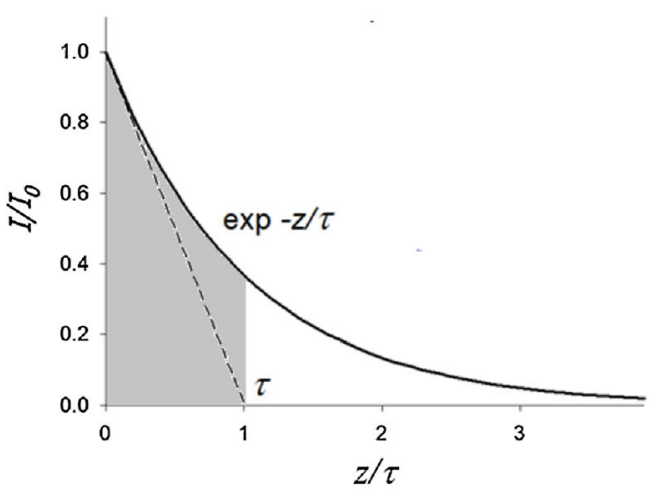

(b)

Fig. 1-The information depth in the Laplace space methodology limited by absorption of the radiation: (a) the beam optics used in AD - angular dispersion and ED - energy dispersion techniques; $(b)$ variation of the beam intensity with depth (z) below the surface and definition of penetration/information depth $\tau$.

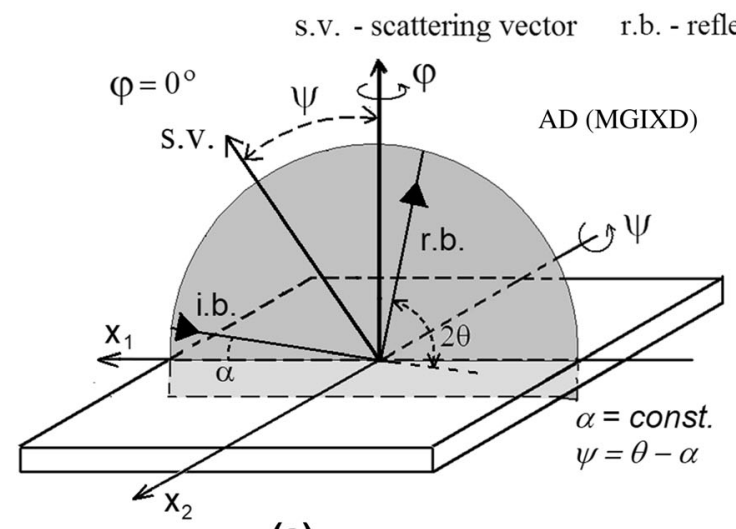

(a)

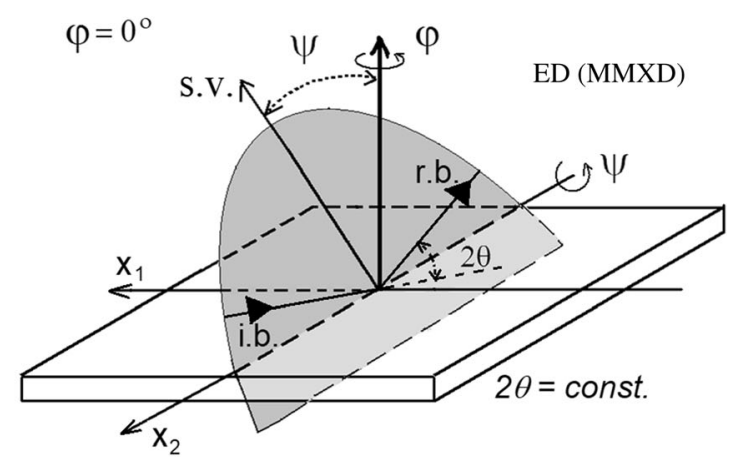

(b)

Fig. 2-Experimental geometries: (a) AD-MGIXD method with the diffraction plane perpendicular to sample surface and for constant $\alpha$ angle, the $\psi_{h k l}$ angle depends on the $2 \theta_{h k l}$ angle, which corresponds to different $h k l$ reflection; (b) ED-MMXD method in which the $\psi$ angle depends on the tilt of the diffraction plane, while $2 \theta$ angle remains constant. The measurements are performed for $\varphi=0$ deg and then for $\varphi=90$ deg.

$$
\langle a(\phi, \psi)\rangle_{h k l}=\left[F_{i j}(h k l, \phi, \psi) \sigma_{i j}\right] a_{0}+a_{0}
$$

where: $F_{i j}(h k l, \phi, \psi)$ are the X-ray stress factors (XSFs) ${ }^{[36]}$ and $\phi$ is a chosen azimuthal angle (for details see References 21, 23, 34, 35, 37, and 38).

The angle-dispersive $2 \theta_{h k l}$ scans performed on the XPert PANalytical X-ray diffractometer were collected in the continuous scan mode with a step size of $0.02 \mathrm{deg}$. In order to decrease the uncertainty of the determined peak position and to minimize the error caused by sample displacement in the $\mathrm{z}$-direction, the parallel beam configuration was used in the measurements. The incident beam optics was equipped with a Göbel mirror and Soller slit (0.04 rad.) with the fixed divergence slit $\left(1 / 2^{\circ}\right)$, whereas the diffracted beam optics was equipped with a parallel plate collimator $(0.18 \mathrm{deg})$ and Soller slit (0.04 rad). Diffraction spectra were collected for $\phi=0$ and $90 \mathrm{deg}$ using proportional point detector ( $c f$., Figure 2). The range of $2 \theta_{h k l}$ scanning was 30 to
$150 \mathrm{deg}$ and the measurements were performed for three incidence angles $\alpha=10,15$, and $20 \mathrm{deg}$. In this measurements, a relatively large surface, at least $3 \times 5 \mathrm{~mm}^{2}$, was irradiated due to low values of the incident angle and the size of the diffracted beam was not limited, $c f$., Figure 1(a). Because of a large grain size in the studied sample (with mean diameter of about to $250 \mu \mathrm{m}$, see Section III), the gauge volume was limited only to the top of the outer layer of the grains. Consequently, the estimated number of grains contributing in diffraction was over 300. This grain statistics and the state of the significantly deformed mechanically polished surface layer provided smooth diffraction peaks sufficient for stress analysis. Registered double $\mathrm{K}_{\alpha 1}$ and $\mathrm{K}_{\alpha 2}$ peaks ( $\mathrm{Cu}$ radiation) were fitted using pseudo-Voigt function, ${ }^{[39]}$ and interplanar spacings were calculated from the determined $2 \theta_{h k l}$ positions using Bragg's law.

Residual stresses $\sigma_{i j}$ and stress-free lattice parameter $a_{0}$ were determined by fitting the lattice parameters 
$a(\phi, \psi)_{h k l}$ calculated from Eq. [2] to the experimental ones. With this aim the least square procedure was applied. ${ }^{[38,40]}$ To exclude possible experimental errors caused by diffractometer misalignment, a standard powder reference sample (LaB6 no. SRM 660 by the US National Institute of Standard and Technology NIST) was also measured under the same condition as the examined specimens.

The relatively high absorption of classical low-energy $\mathrm{X}$-rays $\left(\mathrm{Cu} \mathrm{K} \mathrm{K}_{\alpha}\right.$ radiation) limits the informative volume obtained using MGIXD method to a very shallow depth (up to ca. $1 \mu \mathrm{m}$ ). Therefore, the evolution of residual stress in deeper regions of the sample was performed using energy-dispersive diffraction with synchrotron high energy radiation.

\section{B. ED-MMXD Method}

Energy-dispersive diffraction (ED) with synchrotron radiation is a technique convenient for the investigation of residual stresses or structural properties and their gradients in the near subsurface region of polycrystalline materials. A high intensity, wide energy range (up to $90 \mathrm{keV}$ ) and perfect collimation of the synchrotron beam, as well as the possibility of simultaneous registration of many $h k l$ reflections allow for investigating materials up to much deeper regions in the sample than for classic laboratory X-ray diffractometers. Measurements are performed at the desired fixed $2 \theta$ diffraction angle with white synchrotron beam (Figure 2(b)). The Bragg's law relates the interplanar spacings $\langle d(\phi, \psi)\rangle_{h k l}$ to corresponding energies $E_{h k l}$ of the diffraction lines:

$$
\langle d(\phi, \psi)\rangle_{\{h k l\}}=\frac{h c}{2 E_{h k l} \sin \theta}
$$

where $h$ is a Planck's constant and $c$ is the velocity of light.

The interplanar spacings are determined for a given azimuthal angle $\phi$ and different $\psi$-tilts of the scattering vector, analogically as in the classical $\sin ^{2} \psi$ method. ${ }^{[27,33,37]}$ The $\psi$-tilt was around the axis being the intersection of the diffraction plane with the sample surface (Figure 2(b)). Each reflection measured with energy $E_{h k l}$ and selected $2 \theta$ diffraction angle corresponds to different (average) penetration depth, which in the case of $\psi$-tilt can be calculated from the equation:

$$
\tau=\frac{\sin \theta \cos \psi}{2 \mu\left(E_{h k l}\right)}
$$

where $\mu\left(E_{h k l}\right)$ is the energy dependent linear absorption coefficient.

The method of residual stress determination using the ED technique with synchrotron radiation is widely described in the literature (e.g., References 28, 40 through 45).

In the present work, the ED measurements were performed in the reflection mode using a white beam with wavelength in the range $\lambda$ : $0.3-0.18 \AA$ (corresponding to energy range E of 40-68 keV) on the EDDI@BESSYII beamline. ${ }^{[30]}$ Low-energy solid-state Ge detector was used to collect the diffraction data.
The primary beam cross-section was equal to $0.5 \times$ $0.5 \mathrm{~mm}^{2}$, and the angular divergence in the diffracted beam was restricted by a double slit system with apertures of $0.03 \times 5 \mathrm{~mm}^{2}$ to $\Delta \theta \leq 0.005 \mathrm{deg}$ ( $c f$., Figure 1(b)). The scattering angle $2 \theta$ was chosen to be equal 10 and $16 \mathrm{deg}$. For these optics the surface of at least $1.5 \mathrm{~mm}^{2}$ is seen as the information area (estimated on the basis of References 28 and 29), which corresponds to about 30 grains in the studied sample. In spite of a small number of grains in the information gauge, the diffraction peaks were sufficient for the stress analysis especially due to deformation of the near surface layer during polishing (due to reduction of the coherent diffraction volume and disorientations between the subgrains).

In the used MMXD method, ${ }^{[24]}$ the residual stress analysis is based on the ED- $\psi$ synchrotron X-ray diffraction measurement performed for multiple $h \mathrm{kl}$ reflections. The measurements were performed in the reflection $\psi$-mode (cf., Figure 2(b)) for $\phi=0$ and $90 \mathrm{deg}$, in steps of $\Delta \psi=4 \mathrm{deg}$ for $\psi=(0 \mathrm{deg} ; 72 \mathrm{deg})$ and $\Delta \psi=2 \mathrm{deg}$ for $\psi=(74 \mathrm{deg} ; 80 \mathrm{deg})$. To determine interplanar spacings $\langle d(\phi, \psi)\rangle_{h k l}$ from Eq. [3], the diffraction peaks were fitted using the pseudo-Voigt function. Reference $\mathrm{Au}$ powder was used to exclude geometrical errors due to the instrument misalignment. Subsequently, data were grouped for strictly chosen penetration depths in order to perform the residual stress analysis layer by layer in the sample and to get a much deeper profile than in the case of the MGIXD method. The benefit of this approach - in contrast with classical ED stress analysis - is that the depth profile is not averaged over a wide range of the depth. ${ }^{[24]}$ This can be done because in the analysis more than one $h \mathrm{kl}$ reflection corresponding to the given step of the penetration depth are used (i.e., multireflection approach). The penetration depth is still expressed by Eq. [4], while the stresses $\sigma_{i j}$ and stress-free lattice parameter $a_{0}$ are calculated as in the MGIXD method accordingly to Eq. [2].

\section{SAMPLE PREPARATION AND CHARACTERIZATION}

A commercially pure tungsten sample $\left(5 \times 5 \mathrm{~mm}^{2}\right)$ was mechanically non-directionally polished using silicon carbide grinding papers, grid from 500 up to 3000 . An average roughness $\mathrm{Ra}=73 \mathrm{~nm}$ was measured by use of the WYKO NT9300 (Veeco) profiler (surface topography is shown in Figure 3(a)). The electron backscatter diffraction measurement (the EBSD map is shown in Figure 3(b)) revealed almost equiaxed grains with average size equal to $250 \mu \mathrm{m}$. The measured hardness of the polished material was equal to $463 \mathrm{HV}$. According to Reference 45, in the case of tungsten such hardness value corresponds to yield strength above $890 \mathrm{MPa}$.

Crystallographic texture of the studied sample was characterized by X-ray diffraction method. To perform this, the Empyrean Panalytical X-ray diffractometer was used for measurement of the incomplete pole figures 110 , 


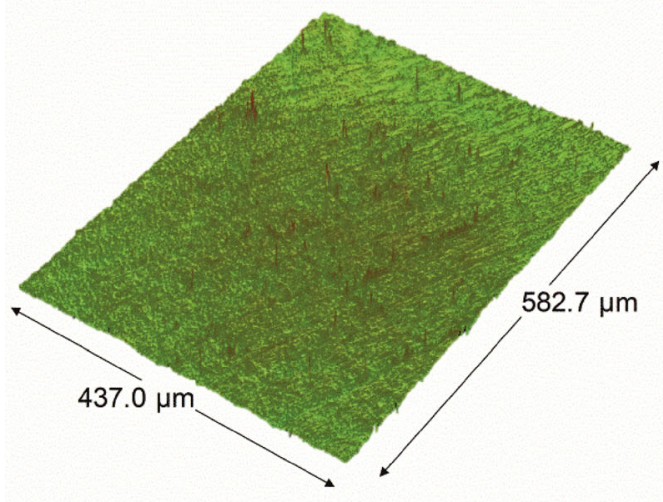

(a)

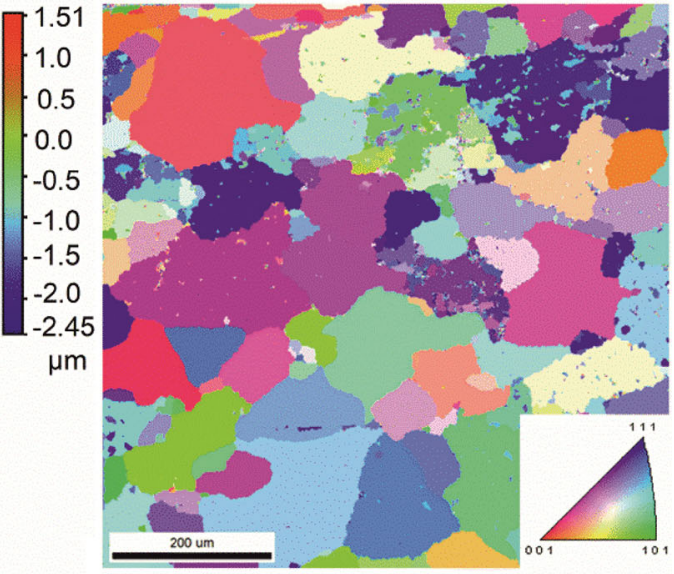

(b)

Fig. 3-Topography of the polished W sample, measured using WYKO profiler (a) and the EBSD orientation map of initial sample (b).

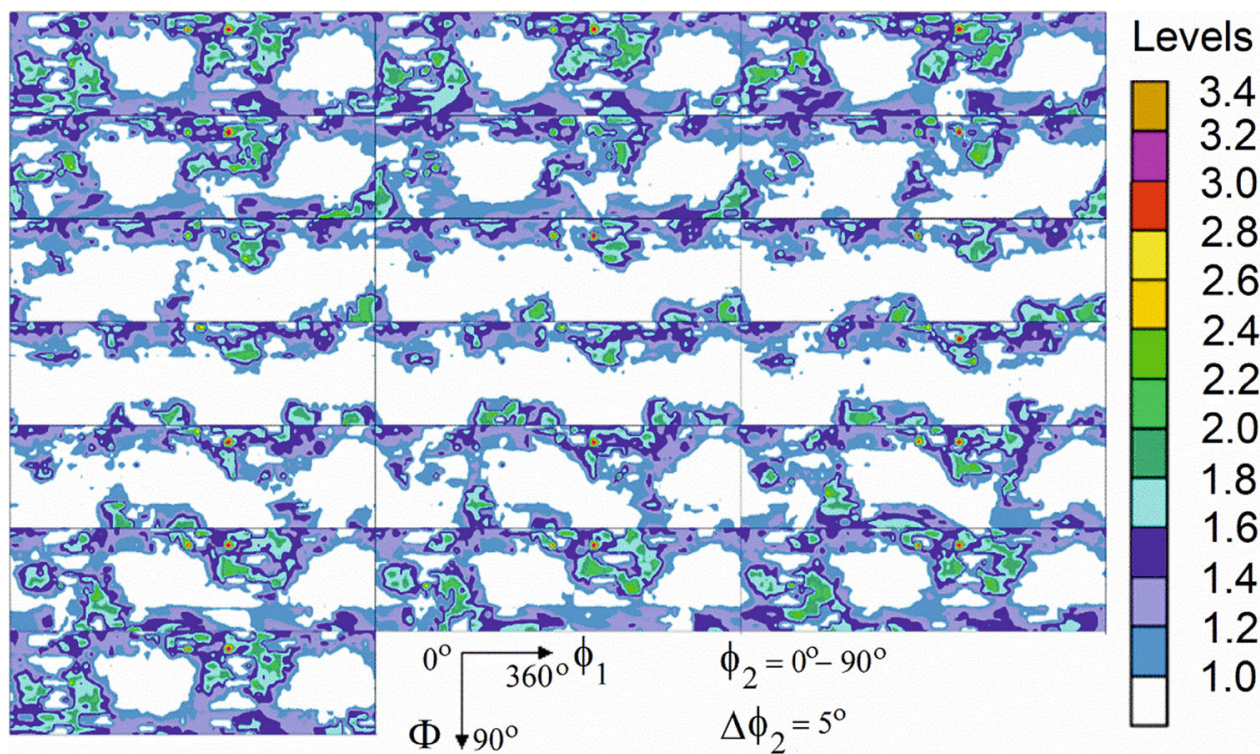

Fig. 4 - Orientation distribution functions (ODF) determined using $\mathrm{Cu}$ radiation for the polished tungsten sample by definition not showing any symmetry. The sections through Euler space with the step of 5 deg are presented along the $\phi_{2}$.

200,211 and 310 by the Schulz reflection technique ${ }^{[46]}$ and the commercial LaboTex software, ver. 3.0.29 by LaboSoft Company ${ }^{[47]}$ was applied for calculation of the orientation distribution function (ODF). Relatively low and irregular texture intensities, characteristic for coarse grains, can be seen in Figure 4.

In calculations of the X-ray stress factors $\left(F_{i j}\right.$ in Eq. [2]), the single crystal elastic constants equal to: $C_{11}=501 \mathrm{GPa}, C_{12}=198 \mathrm{GPa}, C_{44}=151.4 \mathrm{GPa}^{[48]}$, and the ODF shown in Figure 4 were taken into account using the Eshelby-Kröner method. ${ }^{[36,37]}$ It should be emphasized that tungsten crystals exhibit almost perfect isotropic elastic properties with Zener ratio $A$ very close to $1(A=0.999)$. Consequently, it was found that three models (Voigt, Eshelby-Kröner, and Reuss methods ${ }^{[33,37]}$ ) for calculation of the X-ray stress factors give exactly the same result, regardless of whether the measured texture or random texture was used in the calculations. Moreover, it was verified that the X-ray elastic constants ${ }^{[37]}\left(s_{1}=-0.71 \times 10^{-6} \mathrm{MPa}^{-1}\right.$ and $1 / 2 s_{2}$ $\left.=3.21 \times 10^{-6} \mathrm{MPa}^{-1}\right)$, calculated assuming random texture, are practically independent of the reflection $h k l$ and model used. It can be concluded, that for elastically isotropic tungsten, the $s_{1}, s_{2}$, and $F_{i j}$ factors do not depend on the reflection $h k l$ and crystallographic texture, which greatly simplifies stress analysis, especially in the case of the multireflection methods.

\section{RESULTS AND DISCUSSION}

The results of both experiments, performed using the AD-MGIXD and ED-MMXD methods, were analyzed assuming a biaxial stress state in the information gauge 
volume. Therefore, the $\sigma_{11}$ and $\sigma_{22}$ stress tensor components were determined from measurements performed for $\phi=0$ and $90 \mathrm{deg}$ (Figure 2), while the other components in Eq. [2] were assumed equal to zero. The shear stresses $\sigma_{12}, \sigma_{13}$ and $\sigma_{23}$ should be insignificant for the non-directionally polished sample, without any distinguishable direction on the surface plain. Moreover, the force perpendicular to the surface can be neglected in the shallow gauge volume studied in this work (up to $9 \mu \mathrm{m}$ ), leading to the assumption $\sigma_{33}=0$.

It should be noted that the least square procedure used in this work (based on Eq. [2]) was applied simultaneously for all the results obtained for both angles $\phi=0$ and $90 \mathrm{deg}$ in order to determine $\sigma_{11}, \sigma_{22}$ and $a_{0}$ values. To do this, the weighted least-squares method (WLSM), as described in our previous work, ${ }^{[40]}$ was used (the measurement weight is equal to the inverse of the square of experimental uncertainty). In Figures 5 through 7, the experimental and fitted $a(\phi, \psi)_{\{h k l\}} v s$. $\sin ^{2} \psi$ plots are compared and, additionally, the values of $R^{2}$ (coefficient of determination-COD) ${ }^{[49]}$ are provided. Although in the general case the fitted $a(\phi, \psi)_{\{h k l\}}$ $v s$. $\sin ^{2} \psi$ functions can be non-linear (for anisotropic crystals, as for example $\mathrm{Ni}^{[40]}$ ), perfectly linear dependences were obtained for the studied tungsten sample in spite of different $h k l$ reflections used (Figures 5 through 7). This is the effect of the elastic isotropy of single crystals in calculations of the stress factors $F_{i j}$ as discussed in Section II.

\section{A. AD-MGIXD Classical X-ray Measurements}

The AD-MGIXD method was used to measure lattice parameters $\langle a(\phi, \psi)\rangle_{\{h k l\}} v s . \sin ^{2} \psi$ plots using different $h k l$ reflections, for constant values of the incident angle and for two azimuthal $\phi$ angles. The so obtained experimental $\sin ^{2} \psi$ functions, fitted by lines accordingly to Eq. [2], are shown in Figure 5. It can be seen that the plots are almost perfectly linear (as confirmed by $R^{2}$ values in the range 0.98 to 0.99 ) and exhibit similar slopes for two azimuthal angles $\phi=0$ and $90 \mathrm{deg}$. Such results are expected because of the isotropic elastic properties of tungsten and the symmetry of the nondirectional polishing treatment. As a result, similar stresses for the $x_{1}$ and $x_{2}$ directions corresponding to $\phi=0$ and $90 \mathrm{deg}$ were found, as shown in Figure 8.

In Figure 5, it can be noted that the uncertainties of the determined $\langle a(\phi, \psi)\rangle_{\{h k l\}}$ parameters depend on the $h k l$ reflection because of different values of $2 \theta_{h k l}$. The departure of the measured $\langle a(\phi, \psi)\rangle_{\{110\}}$ from the fitted line is observed for all presented plots, probably due to systematic error which, however, remains almost in the range of experimental uncertainty.

\section{B. ED-MMXD Measurement Using Synchrotron Radiation}

The ED synchrotron measurements were conducted twice for given scattering angles $2 \theta=10$ and $16 \mathrm{deg}$. Subsequently, the lattice parameters $\langle a(\phi, \psi)\rangle_{\{h k l\}}$ determined for different tilt angles $\psi$ and different $h k l$ reflections (related to energies through Eq. [3]) but corresponding to the same penetration depth within the range $\tau \pm 1 \mu \mathrm{m}$ were selected (MMXD method ${ }^{[24]}$ ). The $\langle a(\phi, \psi)\rangle_{\{h k l\}} v s \cdot \sin ^{2} \psi$ functions corresponding to the chosen penetration depths, fitted by lines accordingly to Eq. [2], are shown in Figure 6 for $2 \theta=10 \mathrm{deg}$ and in Figure 7 for $2 \theta=16 \mathrm{deg}$. It can be seen that the plots containing results obtained for different $h k l$ reflections are linear and the multireflection data fit well to straight lines, as shown in Figures 6 and 7. As in the case of the MGIXD method, the slopes of $\langle a(\phi, \psi)\rangle_{\{h k l\}} v s \cdot \sin ^{2} \psi$ plots are generally similar for azimuthal angles $\phi=0$ and $90 \mathrm{deg}$ (with some exceptions, e.g., for $\tau=1 \mu \mathrm{m}$ ), which means that the stresses in these directions are approximately equal ( $c f$., also Figure 8). In spite of worse fitting quality for $2 \theta=10\left(R^{2}\right.$ is in the range: 0.62 to 0.97$)$, the obtained stresses and slopes coincide with those determined with $2 \theta=16 \mathrm{deg}\left(R^{2}\right.$ is in the range: 0.88 to 0.99 ).

It should be emphasized that, in the case of MMXD method, the scatter of the experimental points around the fitted $\langle a(\phi, \psi)\rangle_{\{h k l\}} v s$. $\sin ^{2} \psi$ lines is more significant compared to the MGIXD method. Such scatter can be caused especially by the low statistics of grains in the case of the ED measurements. Moreover, the disagreement between the experimental and theoretical (fitted) lines can result from the assumptions introduced in the analysis, i.e., the so-called second-order stresses ${ }^{[50,51]}$ were neglected and the shear stresses sigma $\sigma_{13}$ and $\sigma_{23}$ were assumed to be equal to zero. Another reason of the $\langle a(\phi, \psi)\rangle_{\{h k l\}} v s \cdot \sin ^{2} \psi$ plots nonlinearity is the stress gradient in the information depth.

\section{Residual Stress Profile}

The evolution of residual stresses and stress-free parameter $a_{0}$ determined using both MGIXD and MMXD methods for different penetration depths $\tau$ are shown in Figures 8 and 9, respectively.

It should be stated that the stresses measured using the Laplace space methods are in fact defined as the average values over the volume penetrated by X-rays, $i$. e.:

$$
\bar{\sigma}_{i j}(\tau)=\frac{\int_{0}^{\infty} e^{-z / \tau} \sigma_{i j}(z) \mathrm{d} z}{\int_{0}^{\infty} e^{-z / \tau} \mathrm{d} z}
$$

where $z$ is a "real depth" under the sample surface, while $\tau$ is the "penetration depth" (calculated from Eq. [1] or [4]).

It can be noticed that the numerator and denominator of the above equation takes the form of the Laplace transform with respect to $s=1 / \tau$. In order to find out the real depth profile of the stress $\sigma_{i j}(z)$, the inverse Laplace transformation can be applied. ${ }^{[32]}$

Introducing a new variable $s=1 / \tau$, the mean stresses $\bar{\sigma}_{i j}(\tau)$ determined with absorption weight can be expressed as:

$$
\bar{\sigma}_{i j}(s)=\frac{\int_{0}^{\infty} e^{-z s} \sigma_{i j}(z) \mathrm{d} z}{\int_{0}^{\infty} e^{-z s} \mathrm{~d} z}=s \mathscr{L}(s)
$$

where $\mathscr{L}(s)$ denotes Laplace transform of the function $\sigma_{i j}(z)$. 

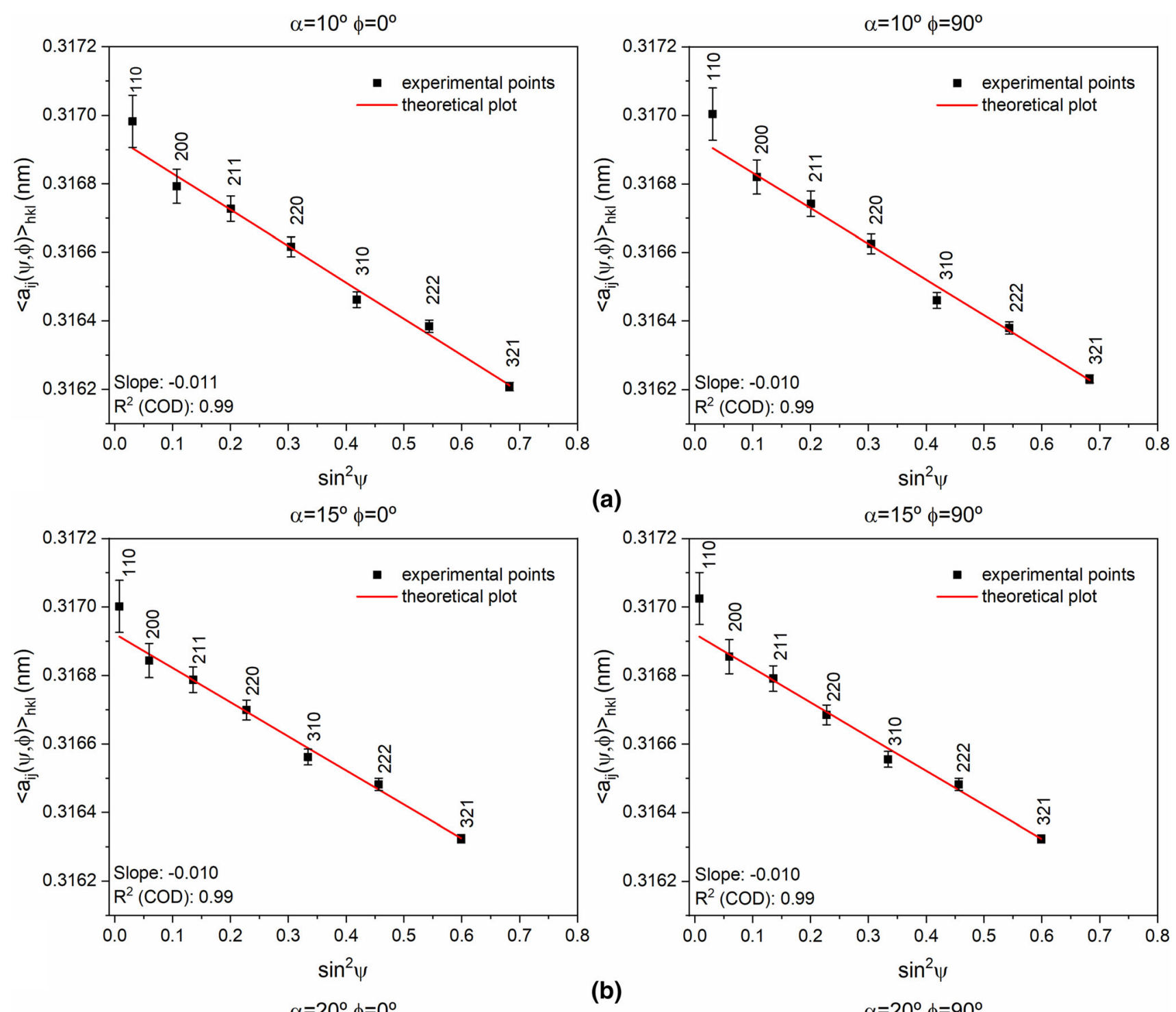

(a)

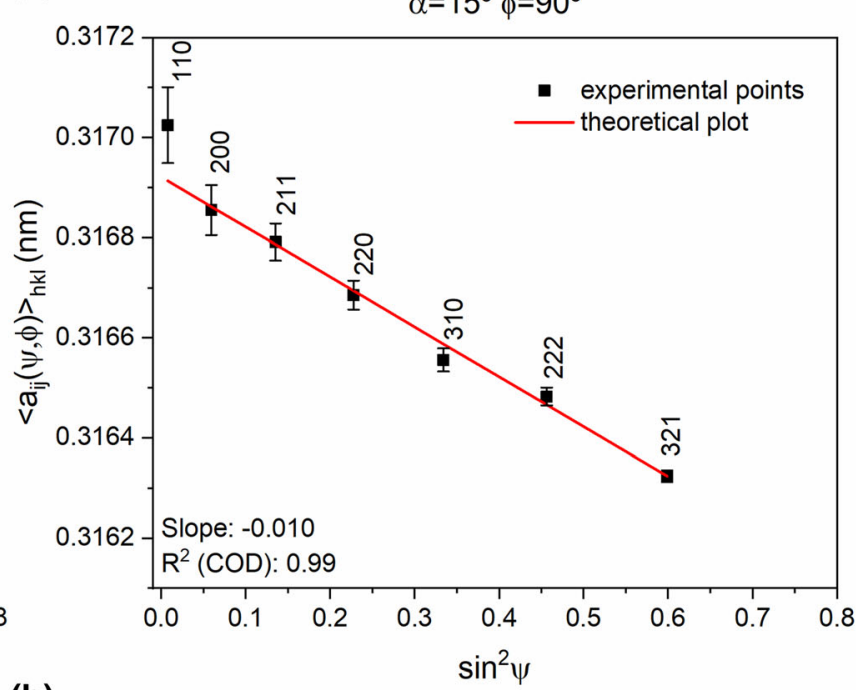

(b)
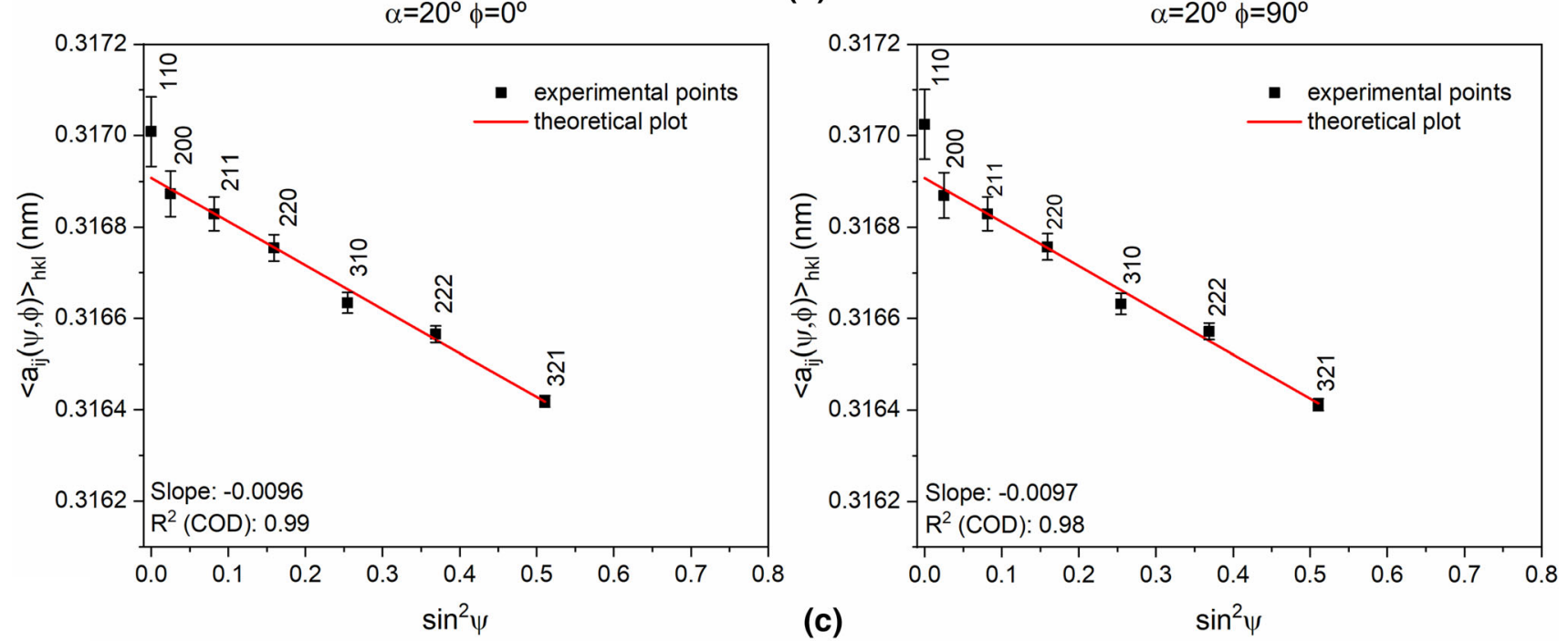

Fig. 5-The $\langle a(\phi, \psi)\rangle_{\{h k l\}} v s \cdot \sin ^{2} \psi$ plots for the mechanically polished $\mathrm{W}$ sample, measured using MGIXD method with $\alpha=10$ deg $(a), 15$ deg (b) and $20 \mathrm{deg}(c)$. The red lines were fitted to the experimental values of $\langle a(\phi, \psi)\rangle_{\{h k l\}}$ using Eq. [2]. The values of $R^{2}$ (COD) and slopes of the fitted lines are presented. Uncertainty of peak position $\delta(2 \theta)=0.01$ deg was assumed (Color figure online). 

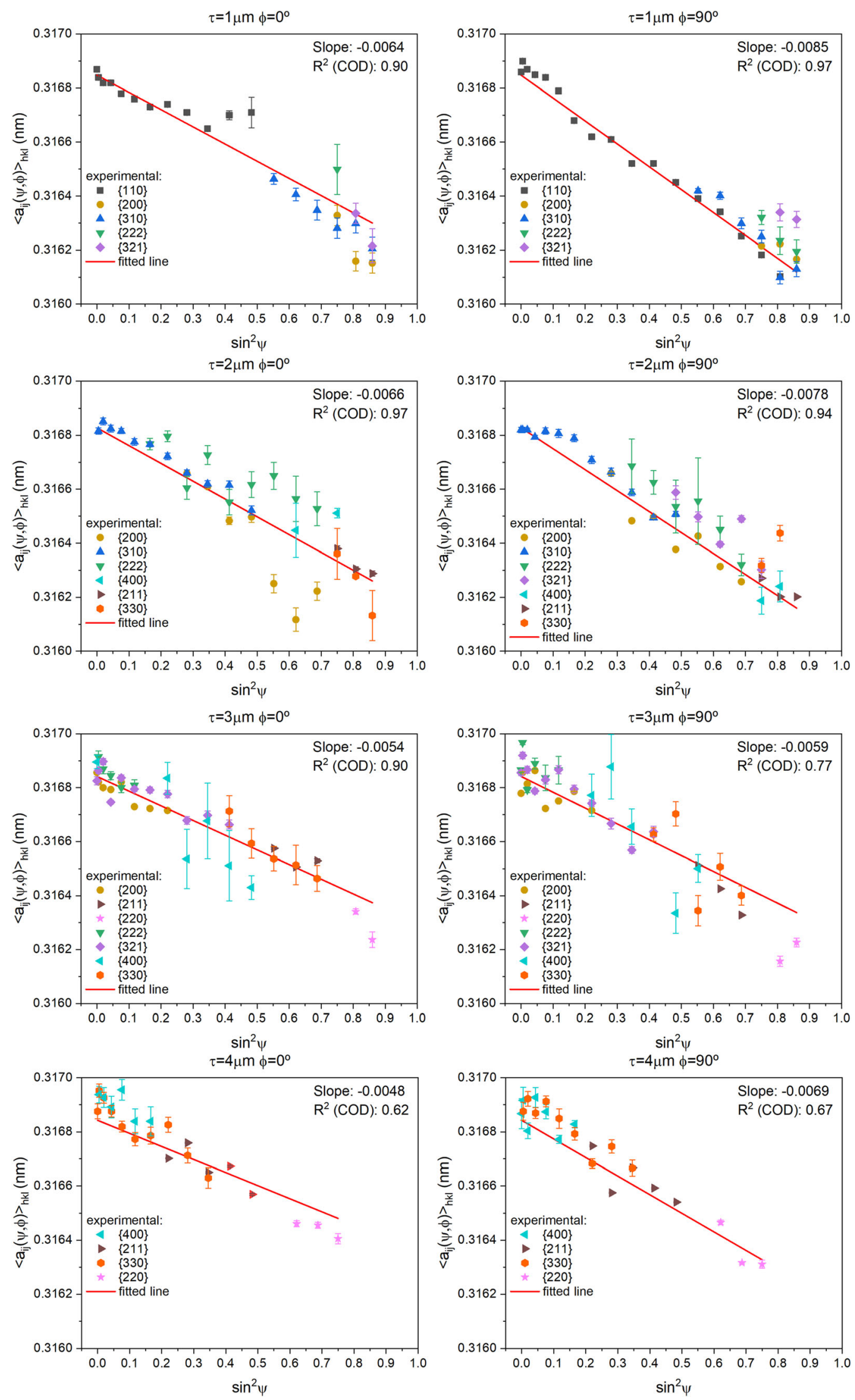

Fig. 6-The example of $\langle a(\phi, \psi)\rangle_{\{h k\}\}} v s \cdot \sin ^{2} \psi$ plots obtained using MMXD method with $2 \theta=10$ deg for different depths in the polished W sample (bar is not visible, if smaller than the symbol indicating the experimental point). The lines were fitted (using Eq. [2]) to the experimental values of $\langle a(\phi, \psi)\rangle_{\{h k l\}}$ determined for given penetration depths $\tau \pm 1 \mu \mathrm{m}$. The values of $R^{2}$ (COD) and slopes of the fitted lines are presented. 

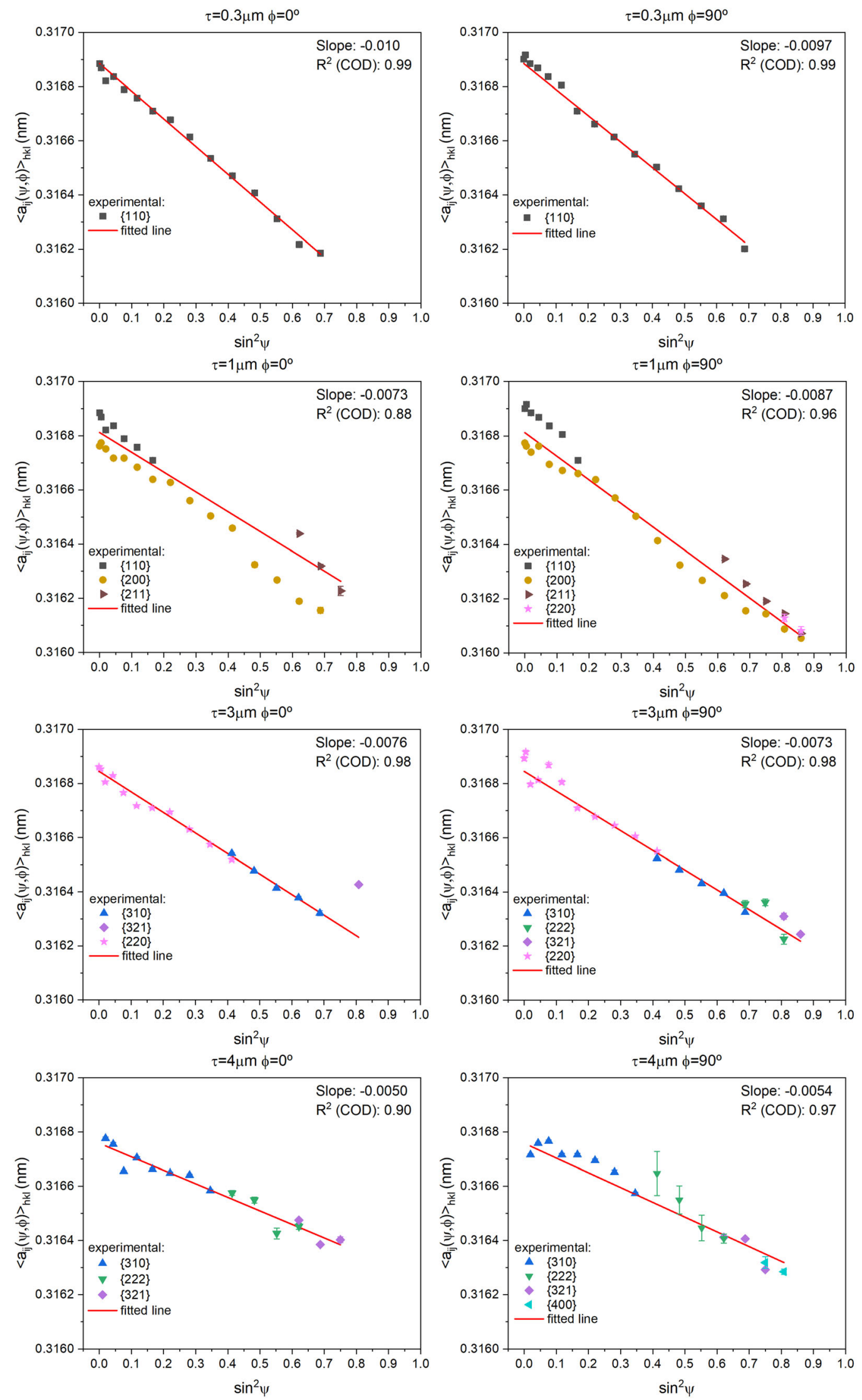

Fig. 7-The example of $\langle a(\phi, \psi)\rangle_{\{h k l\}} v s . \sin ^{2} \psi$ plots obtained using MMXD method with $2 \theta=16$ deg for different depths in the polished W sample (bar is not visible, if smaller than the symbol indicating the experimental point). Similar presentation as in Fig. 6. 

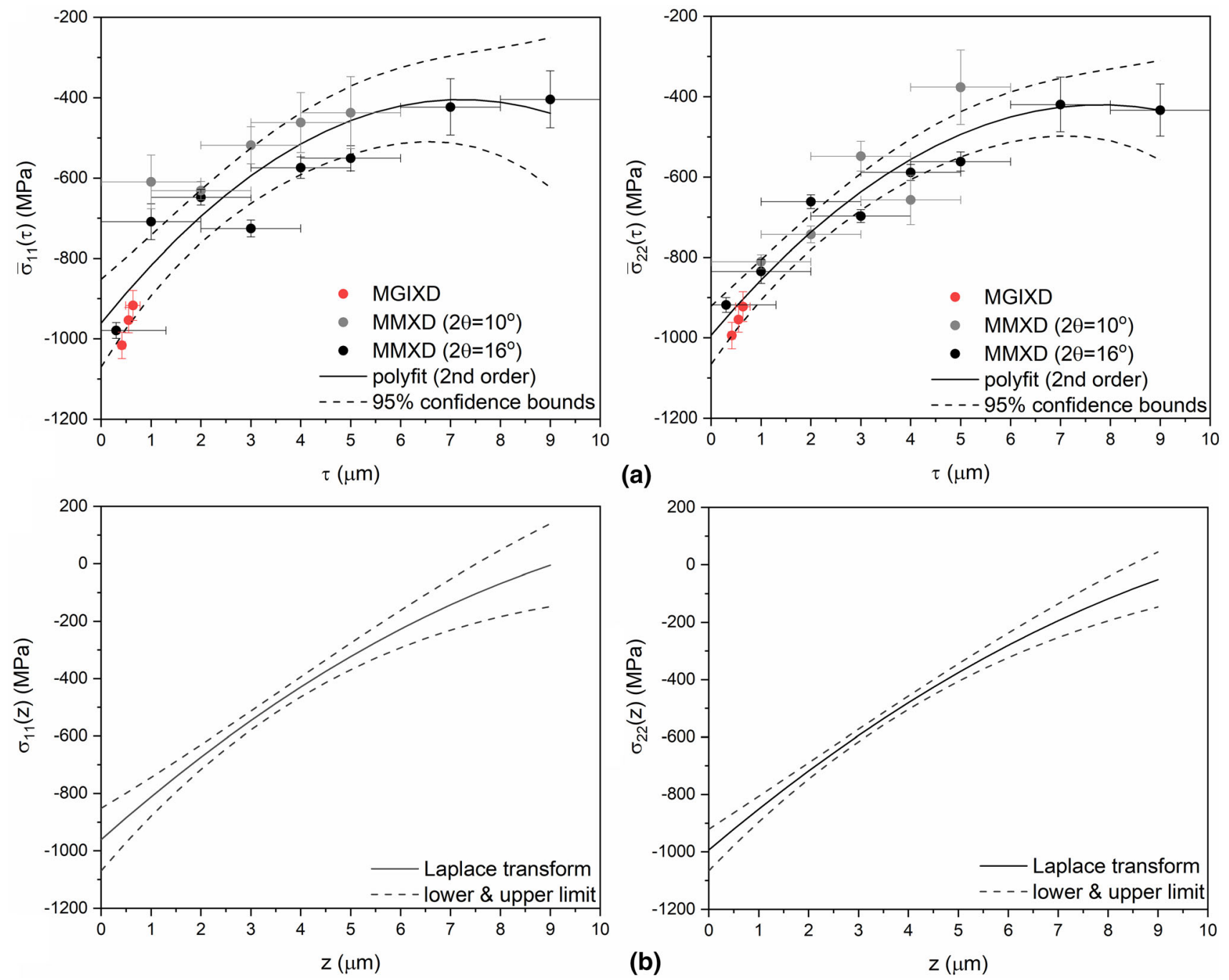

Fig. 8 - Comparison of residual stress profiles in two directions in function of $\tau$-penetration depth $(a)$ and $z$-real depth (b). The uncertainty bounds are given for $95 \%$ confidence. Results gathered from classical diffractometer (MGIXD) and synchrotron experiment (MMXD for two $2 \theta$ angles).

In the present work, the $z$-profile of stress is determined using the method based on a polynomial approximation of the quested stress function $\sigma_{i j}(z),{ }^{[52]}$ i.e.:

$$
\sigma_{i j}(z)=\sum_{n=0}^{N} a_{n} z^{n}
$$

Calculating the Laplace transform $\mathscr{L}(s)$ from $\sigma_{i j}(z)$ and multiplying the product by $s$ (cf. Eq. [6]), the $\bar{\sigma}_{i j}(s)$ and $\bar{\sigma}_{i j}(\tau)$ functions can be obtained:

$$
\bar{\sigma}_{i j}(s)=\sum_{n=0}^{N} a_{n} \frac{n !}{s^{n}} \quad \text { and } \quad \bar{\sigma}_{i j}(\tau)=\sum_{n=0}^{N} n ! a_{n} \tau^{n}=\sum_{n=0}^{N} b_{n} \tau^{n}
$$

where $b_{n}=n ! a_{n}$.

If the experimental $\bar{\sigma}_{i j}(\tau)$ function (cf., Figure 8(a)) in the above equation is approximated by a polynomial with $b_{n}$ coefficients, the coefficients $a_{n}$ of the polynomial given by Eq. [7] can be easily calculated, i.e.:

$$
a_{n}=b_{n} / n !
$$

Therefore, the approximation of the stress profile $v s$. real depth $\sigma_{i j}(z)$ can be found when the $\bar{\sigma}_{i j}(\tau)$ function is approximated by polynomial.

In the analysis performed in this work, it was assumed that the evolution of the stresses $v s$. penetration depth $\bar{\sigma}_{i j}(\tau)$ can be approximated by the second-order polynomial (i.e., $N=2$ in Eq. [8]). The result of least square fitting of the $\bar{\sigma}_{i j}(\tau)$ profile by the second-order polynomial, together with the $95 \%$ confidence bounds for the fitted function, ${ }^{[53]}$ is presented in Figure 8(a) (the meaning of the bounds is that the fitted lines lay within the bounds with confidence of $95 \%$ ). All the results coming from the MGIXD and MMXD methods were taken into account as the experimental points. Finally, the determined profile of the residual stresses vs. "real 


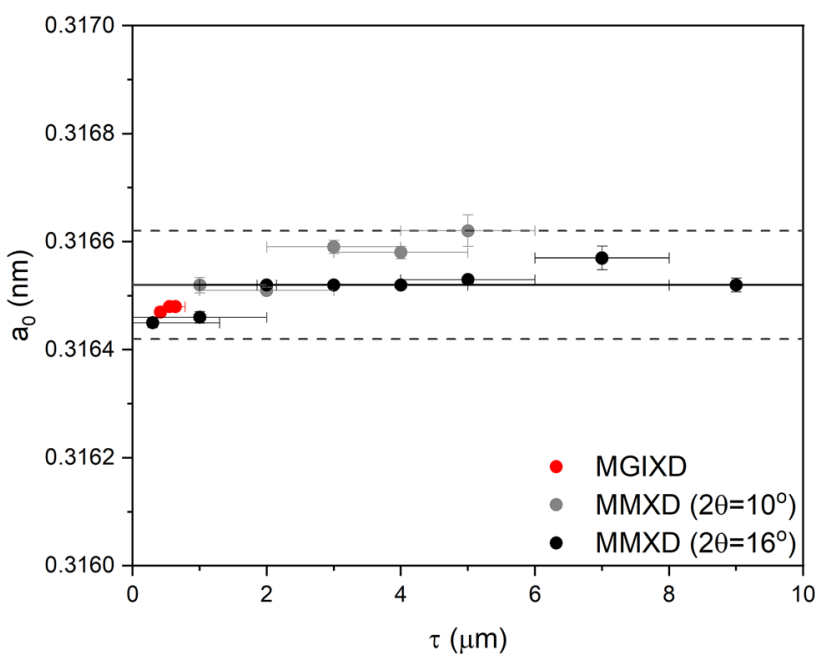

Fig. 9-The profile of lattice parameter $a_{0}$ as a function of $\tau$-penetration depth. Results gathered from classical diffractometer (MGIXD method) and synchrotron experiment (MMXD for two $2 \theta$ angles).

depth" in the sample $\left(\sigma_{11}(z)\right.$ and $\left.\sigma_{22}(z)\right)$ was determined from Eq. [9] and shown in Figure 8(b). The bounds of $\sigma_{11}(z)$ and $\sigma_{22}(z)$ profiles correspond to those estimated for the $\bar{\sigma}_{11}(\tau)$ and $\bar{\sigma}_{22}(\tau)$ functions.

It can be concluded that the stresses $\sigma_{11}(z)$ and $\sigma_{22}(z)$ change significantly with the subsurface depth in the sample, from a high compressive value (about - $1000 \mathrm{MPa}$ ) near the surface of the sample to almost zero value in deeper regions $(z \approx 9 \mu \mathrm{m})$, and the residual stress profiles are similar in both directions determined for $\varphi=0$ and $90 \mathrm{deg}$ ( $c f$. ., Figure 8(b)). The high stress value is reasonable for this material exhibiting hardness equal to $463 \mathrm{HV}$ (yield strength above $890 \mathrm{MPa}$ ) measured in the polished area, which is increased due to significant deformation in the near surface volume. Certainly the hardness very close to surface is higher because the material is severely deformed during mechanical polishing. The determined biaxial stress state is beneficial for the sample due to its compressive character preventing surface and subsurface cracks initiation and propagation. ${ }^{[17]}$

What is more, as shown in Figure 9 the value of $a_{0}$ remains approximately constant with the subsurface depth in the sample. The minor variation of $a_{0}$ with depth (in the margin of $\pm 0.001 \AA$ ) can be caused by the nonzero value of $\sigma_{33}$ stress, which was neglected in the analysis and/or experimental errors due to sample misalignment or beam divergence. The latter effects are difficult to take into account in the analysis; however, the changes of $a_{0}$ (Figure 8) are relatively small compared to the ranges $\langle a(\phi, \psi)\rangle_{\{h k l\}} v$ v. $\sin ^{2} \psi$ evolutions (Figures 5 through 7). Therefore, contrary to the very convincing results regarding stress measurements, the interpretation of the presented $a_{0}$ variation is unjustifiable.

The unique advantage of the experimental techniques used in the present work is the possibility of stress gradient determination in the near surface volume. It should be emphasized that the stress evolution in function of the real depth was found. Due to large absorption of the classical X-rays, only the subsurface stress (down to $1 \mu \mathrm{m}$ ) can be measured using MGIXD method, but application of high energy synchrotron radiation allowed for significantly extending the accessible depth (up to $9 \mu \mathrm{m}$ ). The advantage of the MMXD method $^{[24]}$ is its relatively high spatial resolution in the depth of about $1 \mu \mathrm{m}$, which was unattainable for the classical ED- $\psi$ method. ${ }^{[54]}$ What is important, an excellent continuation of the results vs. penetration depth was obtained using the MGIXD method for small depths (up to about $1 \mu \mathrm{m}$ ) and MMXD method for deeper regions of the sample (cf., Figures 8(a) and 9).

Finally, it should be stated that the studied tungsten sample is very convenient for testing of the stress analysis methodologies due to the material elastic isotropy. In such a case, the stress factors $F_{i j}$ do not significantly depend on the method used for their calculation $^{[33,36]}$; moreover, the $F_{i j}$ factors do not depend on crystallographic texture nor on the $h k l$ reflection. This leads to the linear relations of $\langle a(\phi, \psi)\rangle_{\{h k l\}} v s$. $\sin ^{2} \psi(c f$., Figures 5 through 7) and unique results of the analysis, without the additional model assumptions which are necessary for calculations of $F_{i j}$ factors for anisotropic materials (e.g., for austenitic stainless steel or for nickel, see References 38 and 40).

\section{CONCLUSIONS}

This work reports on the novel multiwavelength method (MMXD), which is a nondestructive approach for residual stress measurements and - in comparison to multireflection grazing incidence X-ray diffraction method (MGIXD)-provides significantly wider subsurface depth of measurement. By using a commercial bulk polycrystalline tungsten, the residual stress generated in the subsurface layers due to mechanical polishing was studied.

The obtained results reveal a significant residual stress gradient present in the subsurface volume of a polished tungsten sample. The compressive stress of about $1000 \mathrm{MPa}$ was determined very close to the polished surface (MGIXD method). Going deeper in the subsurface volume, the residual stresses gradually decrease down to zero value at the depth of about $9 \mu \mathrm{m}$ (MMXD method). Although the stress state remains compressive in the experimentally available range (up to $z=9 \mu \mathrm{m}$, $c f$., Figure 8(b)), the trend of evolution and the approximately zero values at the maximum measured depths indicate that the balancing tensile stress is expected in the deeper regions of the sample.

The almost isotropic elastic properties of tungsten crystallites simplify the analysis of the residual stress state. The value of lattice parameter remains almost constant up to $9 \mu \mathrm{m}$ of the penetration depth, regardless of the method used. Furthermore, the results obtained using MGIXD for sample surface are continued by the MMXD results. High-energy synchrotron radiation allowed for measurements of significantly larger subsurface depths in comparison with classical laboratory $\mathrm{X}$-rays. The results of this work have confirmed that the methods used are complementary, i.e., the MMXD 
method provides experimental information about stress evolution for the depth not available using the MGIXD method, while the MGIXD measurements give more precise results close to the sample surface. The MMXD with synchrotron radiation allowed for determining the depth-dependent stress profile with spatial resolution of $1 \mu \mathrm{m}$, which is much better than in the case of standard ED- $\psi$ measurements. ${ }^{[24]}$

It can be concluded that the MGIXD and MMXD methods are a powerful and unique tool for stress measurement in subsurface volume, which cannot be investigated with other techniques. These methods can be used to study residual stresses resulting from surface finishing processes, such as mechanical polishing.

\section{ACKNOWLEDGMENTS}

This work was financed by grants from the National Science Centre, Poland (NCN): UMO-2014/15/D/ST8/ 00542 and UMO-2017/25/B/ST8/00134. AO has been partly supported by the EU Project POWR.03.02.0000-I004/16. Furthermore, we would like to thank Helmholtz-Zentrum Berlin für Materialien und Energie for the beamtime provided at 7T-MPW-EDDI beamline (BESSY II).

\section{AUTHOR CONTRIBUTIONS}

AO involved in data curation, investigation, and writing original draft preparation. MM-W participated in conceptualization, methodology, software, validation, formal analysis, investigation, writing, review \& editing, project administration, and funding acquisition. AB contributed to conceptualization, writing, review \& editing, and funding acquisition. MK and CG did investigation, writing, review \& editing. SW contributed to investigation and resources. KK did data curation, visualization, writing, review \& editing. MW performed writing, review \& editing. The raw data required to reproduce these findings are available to download from [http://doi.org/10.17632/6zz348t2dk.4].

\section{CONFLICT OF INTEREST}

The authors declare that they no conflicts of interest.

\section{OPEN ACCESS}

This article is licensed under a Creative Commons Attribution 4.0 International License, which permits use, sharing, adaptation, distribution and reproduction in any medium or format, as long as you give appropriate credit to the original author(s) and the source, provide a link to the Creative Commons licence, and indicate if changes were made. The images or other third party material in this article are included in the article's Creative Commons licence, unless indicated otherwise in a credit line to the material. If material is not included in the article's Creative Commons licence and your intended use is not permitted by statutory regulation or exceeds the permitted use, you will need to obtain permission directly from the copyright holder. To view a copy of this licence, visit http:// creativecommons.org/licenses/by/4.0/.

\section{REFERENCES}

1. Coefficients of Linear Thermal Expansion. https://www. engineeringtoolbox.com/linear-expansion-coefficients-d_95.html. Accessed 25 July 2019.

2. Densities of Metals and Elements Table | Engineers Edge |. www. engineersedge.com, https://www.engineersedge.com/materials/ densities_of_metals_and_elements_table_13976.htm. Accessed 25 July 2019 .

3. The thermal conductivity of pure metals. https://www.electronicscooling.com/1999/01/the-thermal-conductivity-of-pure-metals/. Accessed 25 July 2019.

4. Tungsten Price 2019 [Updated Daily]. https://metalary.com/ tungsten-price/. Accessed 25 July 2019.

5. J.W. Coenen, Y. Mao, J. Almanstötter, A. Calvo, S. Sistla, H. Gietl, B. Jasper, J. Riesch, M. Rieth, G. Pintsuk, F. Klein, A. Litnovsky, A.V. Mueller, T. Wegener, J.-H. You, Ch. Broeckmann, C. Garcia-Rosales, R. Neu, and C.H. Linsmeier: Fusion Eng. Des., 2017, vol. 124, pp. 964-68.

6. G. Marinelli, F. Martina, S. Ganguly, S. Williams, H. Lewtas, D. Hancock, S. Mehraban, and N. Lavery: J. Nucl. Mater, 2019, vol. 522, pp. $45-53$

7. M. Rieth, S.L. Dudarev, S.M. Gonzalez de Vicente, J. Aktaa, T. Ahlgren, S. Antusch, D.E.J. Armstrong, M. Balden, N. Baluc, M.F. Barthe, W.W. Basuki, M. Battabyal, C.S. Becquart, D. Blagoeva, H. Boldyryeva, J. Brinkmann, M. Celino, L. Ciupinski, J.B. Correia, A. De Backer, C. Domain, E. Gaganidze, C. GarcíaRosales, J. Gibson, M.R. Gilbert, S. Giusepponi, B. Gludovatz, H. Greuner, K. Heinola, T. Höschen, A. Hoffmann, N. Holstein, F. Koch, W. Krauss, H. Li, S. Lindig, J. Linke, Ch. Linsmeier, P. López-Ruiz, H. Maier, J. Matejicek, T.P. Mishra, M. Muhammed, A. Muñoz, M. Muzyk, K. Nordlund, D. Nguyen-Manh, J. Opschoor, N. Ordás, T. Palacios, G. Pintsuk, R. Pippan, J. Reiser, J. Riesch, S.G. Roberts, L. Romaner, M. Rosiński, M. Sanchez, W. Schulmeyer, H. Traxler, A. Ureña, J.G. van der Laan, L. Veleva, S. Wahlberg, M. Walter, T. Weber, T. Weitkamp, S. Wurster, M. A. Yar, J.H. You, and A. Zivelonghi: J. Nucl. Mater, 2013, vol. 432, pp. 482-500.

8. Z. Zhang, W. Han, and A. Kimura: J. Plasma Fusion Res. SERIES, 2015, vol. 11, pp. 94-98.

9. T. Palacios García: Phd, E.T.S.I. Caminos, Canales y Puertos (UPM), 2015.

10. A. Dubinko: Plastic Deformation of Tungsten Under Fusion-Plasma Exposure Conditions, Universidad Complutense De Madrid, Madrid, 2019.

11. K. Deprez, S. Vandenberghe, K.V. Audenhaege, J.V. Vaerenbergh, and R.V. Holen: Med. Phys., 2013, vol. 40, p. 012501.

12. Tungsten Applications - Electrical Applications. https://www. azom.com/article.aspx?ArticleID=1262. Accessed 25 July 2019.

13. A. Wronski and A. Foukdeux: J. Less Common Met., 1965, vol. 8, pp. $149-58$.

14. J.R. Stephens: Review of Deformation Behaviour of Tungsten at Temperatures Less than 02 Absolute Melting Temperature, TM X2482, NASA, Washington, DC, 1972.

15. DH Lassila and GTI Gray: J. Phys. IV, 1994, vol. 4, pp. C8-349-C8354.

16. A. Giannattasio, Z. Yao, E. Tarleton, and S.G. Roberts: Philos. Mag., 2010, vol. 90, pp. 3947-59.

17. Y. Yuan, J. Du, M. Wirtz, G.-N. Luo, G.-H. Lu, and W. Liu: Nucl. Fusion, 2016, vol. 56, p. 036021.

18. Chopra et al. United States, US6273786B1, 2001. https:// patentimages.storage.googleapis.com/3f/5e/72/185f1f6b409526/ US6273786.pdf.

19. D. Iglesias, X. Lin, J. Loy, and F. Perez: GE Tube Polishing System, Worcester Polytechnic Institute, 2013. 
20. I. Uytdenhouwen, W. Vandermeulen, Y. Zayachuk, and R. Kemps: JMSE B, 2016, DOI:10.17265/2161-6221/2016.7-8.001

21. S.J. Skrzypek, A. Baczmański, W. Ratuszek, and E. Kusior: $J$. Appl. Cryst., 2001, vol. 34, pp. 427-35.

22. M. Marciszko, A. Baczmański, M. Wróbel, W. Seiler, C. Braham, J. Donges, M. Sniechowski, and K. Wierzbanowski: Thin Solid Films, 2013, vol. 530, pp. 81-84.

23. M. Marciszko, A. Baczmański, K. Wierzbanowski, J.-P. Chopart, A. Lodini, N. Zazi, C. Braham, and W. Seiler: Mater. Sci. Forum, 2014, vol. 783-786, pp. 2091-96.

24. M. Marciszko, A. Baczmański, M. Klaus, C. Genzel, A. Oponowicz, S. Wroński, M. Wróbel, C. Braham, H. Sidhom, and R. Wawszczak: J. Appl. Cryst., 2018, vol. 51, pp. 732-45.

25. L. De Buyser, P. Van Houtte, and E. Aernoudt: Textures Microstruct., 1991, vol. 14-18, pp. 73-78.

26. K. Van Acker, L. De Buyser, J.P. Celis, and P. Van Houtte: $J$. Appl. Cryst., 1994, vol. 27, pp. 56-66.

27. Ch. Genzel, I.A. Denks, J. Gibmeier, M. Klaus, and G. Wagener: Nucl. Instrum. Methods Phys. Res. A, 2007, vol. 578, pp. 23-33.

28. M. Meixner, M. Klaus, and C. Genzel: J. Appl. Cryst., 2013, vol. 46, pp. $610-18$.

29. M. Meixner, M. Klaus, and C. Genzel: J. Appl. Cryst., 2013, vol. 46, pp. 619-27.

30. M. Klaus and F. Garcia-Moreno: J. Large Scale Res. Facil. JLSRF, 2016, vol. 2, p. 40.

31. C. Genzel, I.A. Denks, R. Coelho, D. Thomas, R. Mainz, D. Apel, and M. Klaus: TheJ. Strain Anal. Eng. Des., 2011, vol. 46, pp. $615-25$.

32. C. Genzel: Physica Status Solidi (a), 1996, vol. 156, pp. 353-63.

33. I.C. Noyan and J.B. Cohen: Residual Stress: Measurement by Diffraction and Interpretation, Springer, Berlin, 1987.

34. M. Marciszko, A. Baczmański, C. Braham, M. Wróbel, W. Seiler, S. Wroński, and K. Berent: J. Appl. Crystallogr., 2016, vol. 49, pp. $85-102$.

35. M. Marciszko, A. Baczmański, K. Wierzbanowski, M. Wróbel, C. Braham, J.-P. Chopart, A. Lodini, J. Bonarski, L. Tarkowski, and N. Zazi: Appl. Surf. Sci., 2012, vol. 266, pp. 256-67.

36. U. Welzel, J. Ligot, P. Lamparter, A.C. Vermeulen, and E.J. Mittemeijer: J. Appl. Cryst., 2005, vol. 38, pp. 1-29.

37. V. Hauk: Structural and Residual Stress Analysis by Nondestructive Methods, Elsevier, Amsterdam, 1997.

38. M. Marciszko, A. Baczmański, M. Wróbel, W. Seiler, C. Braham, S. Wroński, and R. Wawszczak: J. Appl. Crystallogr., 2015, vol. 48, pp. $492-509$.
39. P. Thompson, D.E. Cox, and J.B. Hastings: J. Appl. Cryst., 1987, vol. 20, pp. 79-83.

40. M. Marciszko-Wiąckowska, A. Oponowicz, A. Baczmański, M. Wróbel, C. Braham, and R. Wawszczak: J. Appl. Cryst., 2019, vol. 52, pp. $1409-21$

41. D. Apel, M. Meixner, A. Liehr, M. Klaus, S. Degener, G. Wagener, C. Franz, W. Zinn, C. Genzel, and B. Scholtes: Nucl. Instrum. Methods Phys. Res. A, 2018, vol. 877, pp. 24-33.

42. M. Klaus, W. Reimers, and C. Genzel: Powder Diffr., 2009, vol. 24, pp. S82-86.

43. C.H. Genzel, C. Stock, and W. Reimers: Mater. Sci. Eng. A, 2004, vol. 372 , pp. $28-43$.

44. M. Klaus, Ch. Genzel, and H. Holzschuh: Thin Solid Films, 2008, vol. 517 , pp. $1172-76$.

45. A.G. (A. .) Rahstadt () and V.A. (B. A.) Brostrem (): Spravochnik Myetallista (Справочник Металлиста), vol. 2, Mashinostroenie (), Moskva (), 1976.

46. L.G. Schulz: J. Appl. Phys., 1949, vol. 20, pp. 1030-33.

47. LaboSoft - the texture analysis software for Windows. Pole figures processing, texture analysis, ODF calculation with ADC method. http://www.labosoft.com.pl/index.html. Accessed 25 July 2019.

48. R.W. Hertzberg, R.P. Vinci, and J.L. Hertzberg: Deformation and Fracture Mechanics of Engineering Materials, 5th ed., John Wiley \& Sons, Inc., 1937, p. 38.

49. Help Online - Origin Help-Algorithms (Linear Regression), https://www.originlab.com/doc/Origin-Help/LR-Algorithm. Accessed 8 June 2020.

50. A. Baczmanski, P. Lipinski, A. Tidu, K. Wierzbanowski, and B. Pathiraj: J. Appl. Crystallogr., 2008, vol. 41, pp. 854-67.

51. S. Wroński, A. Baczmański, R. Dakhlaoui, C. Braham, K. Wierzbanowski, and E.C. Oliver: Acta Mater, 2007, vol. 55, pp. 6219-33.

52. T. Erbacher, A. Wanner, T. Beck, and O. Vöhringer: J. Appl. Crystallogr., 2008, vol. 41, pp. 377-85.

53. Confidence and Prediction Bounds - MATLAB \& Simulink. https://www.mathworks.com/help/curvefit/confidence-and-predic tion-bounds.html?searchHighlight $=$ simultaneous $\% 20$ prediction \%20bounds\&s_tid=doc_srchtitle. Accessed 3 Feb 2020.

54. Ch. Genzel, C. Stock, B. Wallis, and W. Reimers: Nucl. Instrum. Methods Phys. Res. A, 2001, vol. 467-468, pp. 1253-56.

Publisher's Note Springer Nature remains neutral with regard to jurisdictional claims in published maps and institutional affiliations. 